\title{
Early mantle isotopic and elemental heterogeneity: Evidence from the 3.2 Ga Ruth Well - Regal komatiites, Western Australia
}

\author{
I.S. PUCHTEL ${ }^{1}$, M. HORAN ${ }^{2}$, R.J. WALKER ${ }^{1}$, E.G. \\ NISBET $^{3}$, M. LOCMELIS ${ }^{4}$ \\ ${ }^{1}$ Department of Geology, University of Maryland, College \\ Park, MD 20742, USA (ipuchtel@umd.edu) \\ ${ }^{2}$ Carnegie Science, 5241 Broad Branch Rd. NW, Washington, \\ DC 20015, USA (mhoran@CarnegieScience.edu) \\ ${ }^{3}$ Royal Holloway, University of London, Egham TW20 0EX, \\ UK (e.nisbet@es.rhul.ac.uk) \\ ${ }^{4}$ Missouri University of Science and Technology, Rolla, \\ Missouri 65409, USA (locmelism@mst.edu)
}

Komatiites provide unique insights into the temporal evolution of the chemical composition of portions of the early mantle. We report ${ }^{147} \mathrm{Sm}-{ }^{143} \mathrm{Nd},{ }^{176} \mathrm{Lu}-{ }^{176} \mathrm{Hf},{ }^{187} \mathrm{Re}-{ }^{187} \mathrm{Os}$, and ${ }^{182} \mathrm{Hf}^{-182} \mathrm{~W}$ isotope, and lithophile trace and siderophile element abundance data for the Ruth Well and Regal komatiites of the Pilbara Craton in Western Australia. These komatiite systems were derived from melting in anomalously hot, lithophile trace element depleted, deep mantle plume sources, as evidenced by their Al-depleted signatures. The $\mathrm{Sm}-\mathrm{Nd}$, Lu-Hf, and Re-Os isotope data yield isochron ages consistent with near-contemporaneous emplacement of the Ruth Well and Regal lavas at $\sim 3.2$ Ga. Their mantle sources evolved with suprachondritic long-term $\mathrm{Sm} / \mathrm{Nd}$ and $\mathrm{Lu} / \mathrm{Hf}$ (initial $\varepsilon^{143} \mathrm{Nd}=+0.5 \pm 0.1$ and $+1.1 \pm 0.2, \quad \varepsilon^{176} \mathrm{Hf}=+1.8 \pm 0.2$ and $+4.4 \pm 0.6$ for the Ruth Well and Regal systems, respectively). The Ruth Well komatiite system evolved with long-term subchondritic ${ }^{187} \mathrm{Re} /{ }^{188} \mathrm{Os}=0.296 \pm 16$, in contrast to the near-chondritic ${ }^{187} \mathrm{Re} /{ }^{188} \mathrm{Os}=0.434 \pm 3$ in the Regal system $\left(\gamma^{187} \mathrm{Os}=-2.4 \pm 0.4 v s\right.$. $+0.7 \pm 0.1$, respectively). The calculated total HSE abundances in the two mantle sources are $\sim 55 \%$ (Ruth Well) and $\sim 70 \%$ (Regal) of those in estimates for the bulk silicate Earth, implying a significant siderophile element heterogeneity in the $3.2 \mathrm{Ga}$ mantle. In addition, the Ruth Well komatiite source exhibits a positive ${ }^{182} \mathrm{~W}$ anomaly $\left(\mu^{182} \mathrm{~W}=+13.5 \pm 1.8\right)$. The W-HSE systematics are most consistent with stochastic late accretion of large differentiated planetesimals that would be expected to have created significant coupled HSE abundance and W isotope heterogeneities in the pre-late-accretion mantle. Variable degree mantle melting and melt extraction following late accretion would account for the variations in the Re/Os, $\mathrm{Sm} / \mathrm{Nd}$, and $\mathrm{Lu} / \mathrm{Hf}$ ratios in the mantle sources of the two komatiite systems. The decoupled Nd-Hf isotope systematics of the Ruth Well and Regal komatiites may also require limited involvement of early magma ocean processes, such as silicate-silicate fractionation. 